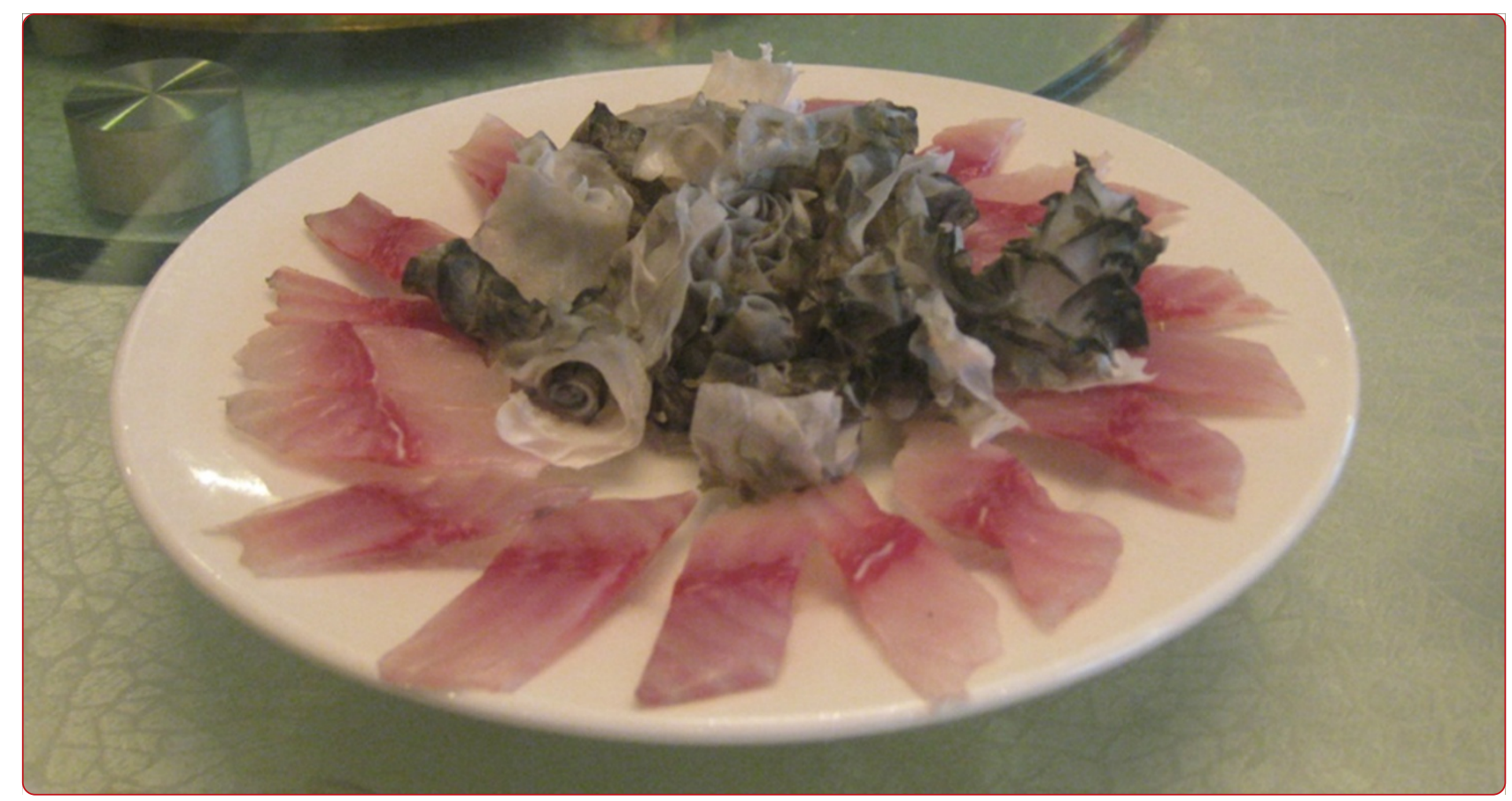

The global epidemiology of clonorchiasis and its relation with cholangiocarcinoma

Qian et al.

() Biomed Central 


\title{
The global epidemiology of clonorchiasis and its relation with cholangiocarcinoma
}

\author{
Men-Bao Qian', Ying-Dan Chen', Song Liang ${ }^{2}$, Guo-Jing Yang ${ }^{3,4}$ and Xiao-Nong Zhou ${ }^{1 *}$
}

\begin{abstract}
This paper reviews the epidemiological status and characteristics of clonorchiasis at global level and the etiological relationship between Clonorchis sinensis infection and cholangiocarcinoma (CCA). A conservative estimation was made that 15 million people were infected in the world in 2004, of which over 85\% distributed in China. The epidemiology of clonorchiasis is characterized by rising trend in its prevalence, variability among sexes and age, as well as endemicity in different regions. More data indicate that $C$. sinensis infection is carcinogenic to human, and it is predicted that nearly 5000 CCA cases attributed to C. sinensis infection may occur annually in the world decades later, with its overall odds ratio of 4.47. Clonorchiasis is becoming one major public health problem in east Asia, and it is worthwhile to carry out further epidemiological studies.
\end{abstract}

Keywords: Clonorchiasis, Clonorchis sinensis, Epidemiology, Cholangiocarcinoma, Odds ratio

\section{Multilingual abstracts}

Please see Additional file 1 for translations of the abstract into the six official working languages of the United Nations.

\section{Review}

Liver flukes are a polyphyletic group of trematodes (phylum Platyhelminthes), including Clonorchis sinensis, Opisthorchis viverrini and Opisthorchis felineus from family opisthorchiidae and Fasciola spp. from family fasciolidae [1-4]. Here, opisthorchiidae, especially C. sinensis is focused on, so liver flukes are specially termed to this family. Adults of liver flukes, localizing in the liver of various mammals including humans, produce eggs which are passed into the intestine. Most of the parasites live in bile ducts, gallbladder and liver parenchyma, causing liver and biliary diseases. Human beings are infected through ingestion of raw or undercooked fish which contains the metacercariae of liver flukes (Figure 1) [1-4].

Cholangiocarcinoma (CCA) is a cancer of the bile ducts. Recent evidences support the fact that CCA is the most severe complication of liver fluke infection,

\footnotetext{
* Correspondence: ipdzhouxn@sh163.net

'National Institute of Parasitic Diseases, Chinese Center for Disease Control and Prevention; WHO Collaborative Center for Malaria, Schistosomiasis and Filariasis; Key Laboratory of Parasite and Vector Biology, Ministry of Health, Shanghai, People's Republic of China

Full list of author information is available at the end of the article
}

and C. sinensis and O. viverrini infections are both classified as "carcinogenic to humans" (Group 1) by the International Agency for Research on Cancer (IARC) in $2009[5,6]$.

Due to the absence of definite information on geographical distribution and disease burden, their public health impact has been underestimated for a long time [7]. Here we review the global epidemiological status and characteristics of clonorchiasis and the etiological relationship between $C$. sinensis infection and CCA.

\section{Epidemiology of clonorchiasis \\ Distribution}

Clonorchiasis is predominantly endemic in east Asia, but it may also occur in other regions where there are immigrants from endemic areas [8]. Due to the growth and movement of population and the rapid development of aquaculture, the fact of clonorchiasis hindering the local economic development is increasingly notified $[2,7]$.

Three large-scale surveys for clonorchiasis have been carried out in mainland of China. The prevalence of clonorchiasis was $0.37 \%$ according to the first national parasite survey involving in 30 Provinces/Municipalities/ Autonomous Regions (P/M/As) between 1988 and 1992 (hereinafter referring as 1992) [9]. Then, it increased to $0.58 \%$ in the second national parasite survey involving in $31 \mathrm{P} / \mathrm{M} /$ As between 2001 and 2004 (hereinafter referring 


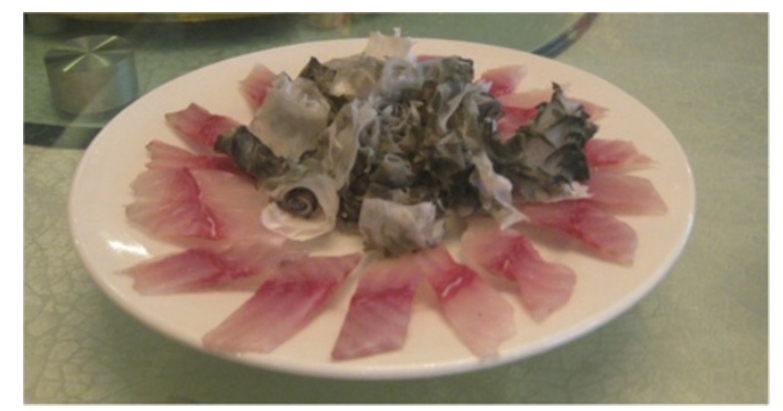

Figure 1 Raw freshwater fish consumed by human beings. The outer layer is raw flesh which has not been cooked anyway, while the inner one is skin of fish which has only been blanched in hot water within a few seconds.

as 2004a) [10,11]. Meanwhile, another special survey for clonorchiasis in 27 endemic P/M/As was carried out between 2002 and 2004 (hereinafter referring as $2004 \mathrm{~b}$ ), which showed the prevalence was $2.40 \%$ and the population infected were 12.49 million [10,11]. The 2004b special survey aimed at clonorchiasis and three Kato-Katz smears were examined for each fecal sample, while the national surveys didn't focus on $C$. sinensis but rather detected any parasite species in a single Kato-Katz smear. Hence, result from the special survey was more reasonable. Clonorchiasis was also endemic in Taiwan, mainly located in Miao-li in the north, Sun-moon Lake in the middle and Mei-nung in the south $[12,13]$ and a prevalence of $0.4 \%-1.0 \%$ was estimated [1]. Thus, a conservative estimation was made that 89000 people were infected in 2004 among the total population of 22.28 million [14]. Based on the hospitalized cases in two hospitals in Hong Kong between 1990 and 1997, out of the 1782 cases with intestinal parasitic diseases, 1162 (65.21\%) were infected with C. sinensis [15]. According to the estimation by WHO in 1995, the population infected in Hong Kong was 333000 [8]. From 1958 to 1991, five local surveys were implemented in Macao and the prevalence varied between $1.40 \%$ and $19.09 \%$. Furthermore, it showed that $13.00 \%-18.87 \%$ people examined in the Laboratory of Public Health in Macao were infected with $C$. sinensis between 1991 and 1997 [16]. It was estimated that 21000 persons were infected with C. sinensis in Macao in 1995 [8]. Consequently, a conservative estimation of population with clonorchiasis in China was 12.93 million in 2004 (Table 1). It was similar to the estimation of 15 million by Lun et al. through analyzing the literature, but the data extracted from the literature spanned quite a long time and were discrepant from the nationally sampling survey in some areas [1].

In the Republic of Korea, clonorchiasis has been becoming a predominant parasitic disease recently. According to the nationally sampling survey in 2004, the total population infected with helminthiases was 1.78 million, of which 1.17 million was with clonorchiasis [17]. In addition, another large scale survey along the 4 major rivers in southern areas in 2006 showed the prevalence reached 17.1\% in Nakdong-gang, $11.2 \%$ in Seomjin-gang, $5.5 \%$ in Youngsan-gang and 4.6\% in Guem-gang [18].

Vietnam is another important endemic area for liver flukes, where clonorchiasis and opisthorchiasis coexist [19]. It was estimated that 1 million people in Vietnam were infected with clonorchiasis in 1995 [8]. According to the newest report by De et al., clonorchiasis is endemic in 21 northern provinces, while opisthorchiasis in 11 southern provinces [20]. The prevalence of clonorchiasis in northern areas varied from $0.2 \%$ to $40.1 \%$. Nevertheless, no nationally sampling survey has yet been implemented and most of the surveys were small scale and non-sampled [19]. Furthermore, it is argued many so-called C. sinensis infected cases are actually infected with other intestinal trematodes [21]. Thus, it is

Table 1 The estimated population infected with C. sinensis globally in 2004

\begin{tabular}{|c|c|c|c|c|c|c|}
\hline \multicolumn{2}{|r|}{ Region } & \multirow[t]{2}{*}{$1990 s^{\#}$} & \multicolumn{3}{|c|}{2004} & \multirow[t]{2}{*}{ Note } \\
\hline & & & Male & Female & Both & \\
\hline \multirow[t]{4}{*}{ China } & Mainland & 4701000 & 7870000 & 4620000 & 12490000 & $\begin{array}{l}\text { Reference }[10] \text { and }[11] \text {. The infected of the male and female is } \\
\text { deduced from the sex ration of } 1.0674 \text { [14] and the respective } \\
\text { prevalence of } 2.94 \% \text { and } 1.84 \%[10,11] \text {. }\end{array}$ \\
\hline & Taiwan & NK & 56155 & 32965 & 89120 & $\begin{array}{l}\text { The total infected is deduced from a conservative prevalence of } \\
0.40 \% \text { [1] and the total population of } 22.28 \text { million [14]. The } \\
\text { estimation for different sexes refers to that in mainland of China. }\end{array}$ \\
\hline & Hong Kong & 333000 & 209825 & 123175 & 333000 & \multirow{2}{*}{$\begin{array}{l}\text { The total infected adopts the estimation by WHO report in } 1995 \\
\text { [8] and the estimation for different sexes refers to that in mainland } \\
\text { of China. }\end{array}$} \\
\hline & Macao & 21000 & 13232 & 7768 & 21000 & \\
\hline \multicolumn{2}{|c|}{ the Republic of Korea } & 950000 & 782383 & 391841 & 1174224 & Reference [17]. \\
\hline \multicolumn{2}{|c|}{ Vietnam } & 1000000 & 630104 & 369896 & 1000000 & \multirow{2}{*}{$\begin{array}{l}\text { The total infected adopts the estimation by WHO report in } 1995 \\
\text { [8] and the estimation for different sexes refers to that in mainland } \\
\text { of China. }\end{array}$} \\
\hline Russia & & 3000 & 1890 & 1110 & 3000 & \\
\hline \multicolumn{2}{|l|}{ Total } & 7008000 & 9563589 & 5546755 & 15110344 & \\
\hline
\end{tabular}

\# According to the figure issued by WHO in 1995 [8]. NK: Not known. 
challenging to arrive at an exact figure of population infected with clonorchiasis in Vietnam. However, taking into consideration of such factors as a huge population at risk (33 million [22]), local habit of eating raw or undercooked fish [21,23], and rapid growth of freshwater fish production [2], 1 million people estimated to be infected with clonorchiasis should not be unreasonable.

C. sinensis is also endemic in far east area of Russia and the population infected estimated by WHO in 1995 were about 3000 [8]. Additionally, 1.22 million people were estimated to be infected with O. felineus [8]. However, the current status in Russia remains unclear.

Recently, eggs of $C$. sinensis were detected from human feces through PCR-based method in O. viverrini endemic area of Thailand [24]. It was found only $64 \%$ individuals were infected with $O$. viverrini and additional $23 \%$ with $C$. sinensis. This extended the traditional knowledge of clonorchiasis. Therefore, whether C. sinensis is also endemic in other traditional endemic areas of $O$. viverrini or $O$. felineus deserves more attention and vice versa.

Little is known on the epidemiological situation of clonorchiasis in Democratic People's Republic of Korea (DPRK). To our best knowledge, only one article has attempted to explore this problem [25]. Out of 137 patients from a hospital in Cheongjin-shi, Hamgyeongbukdo, DPRK, 27 were positive for clonorchiasis using ELISA test. Furthermore, among 133 female immigrants from DPRK to the Republic of Korea, 4 were with clonorchiasis by the same test. Because clonorchiasis was highly endemic in the northeast of China and the Republic of Korea both neighboring to DPRK, and the Korean nationality in the former two countries loves eating raw fish $[10,11,17,18]$, it is probable that clonorchiasis is also an important parasitic disease in DPRK. However, it is difficult to predict the epidemiological situation.

Dozens of clonorchiasis cases have been documented in Malaysia [26-28]. In addition to human cases, infections in cats and farmed fish were also reported [29-31]. However, two local snail species - most likely to act as the intermediate host - were not susceptible to infection [29]. Therefore, local transmission is remaining controversial. Nevertheless, such disease should not be neglected due to high popularity of eating raw fish in traditional festivals [27].

During 1947-1950, C. sinensis occurred in 19 prefectures of Japan. Owing to integrated control programme, clonorchiasis has been successfully controlled. In 1991, no case was found in 1 million stool samples examined [8]. Nowadays, only occasional cases were reported [32,33]. Apparently, clonorchiasis is no longer endemic in Japan.

There are also case reports in other parts of Asia [34,35], Europe [36-46], North America [47,48], South America [49-51], Australia [52] and even Africa [53]. Those reported cases usually were symptomatic, even with severe complications. Due to the lack of knowledge among population and medical organizations and reports bias-tendency to report those with complications, the actual number of persons infected should be higher. The reported cases were mainly immigrants from endemic countries or travelers who had visited endemic countries and eaten raw or undercooked fish.

In summary, clonorchiasis was predominantly endemic in China, the Republic of Korea, Vietnam and part of Russia. It is also probably endemic in DPRK and possibly in Malaysia. The situation in other traditional O. viverrini or $O$. felineus endemic areas is not yet clear. Sporadic human cases are also reported from other countries either due to international travelling or owing to immigration. The conservative estimation of population infected with C. sinensis reached 15 million in 2004 globally, of which over $85 \%$ were in China (Table 1 ).

However, the figure of clonorchiasis in the globe may be complicated by several reasons. First, the eggs of C. sinensis, O. viverrini and O. felineus are morphologically similar and difficult to be distinguished under microscopic examination $[3,54,55]$. Based on recently developed PCR test, $C$. sinensis was also detected in traditional $O$. viverrini endemic areas [24]. Therefore, C. sinensis is probably occurring in traditional endemic areas of O. viverrini and $O$. felineus, which was neglected previously and vice versa. In addition, some minute intestinal flukes whose eggs assemble that of $C$. sinensis also complicate the diagnosis of clonorchiasis [55]. Second, examination techniques contribute to the underestimation of prevalence of clonorchiasis. Current diagnoses are mainly based on fecal examination which is the "gold" standard, particularly Kato-Katz technique and formalin ether technique. However, many studies showed there existed false negative result using these techniques for schistosome, soil-transmitted helminths, as well as $O$. viverrini, especially in low infection intensity [56-61]. Third, early data pertaining to clonorchiasis in some areas may also cause underestimation. Due to the usual resistance to modifying food habit and the growing population in endemic areas, it is reasonable to assume that the population infected is increasing [7]. However, the early data in 1990s were employed to estimate the status of clonorchiasis in Hong Kong, Macao, Vietnam and Russia. Furthermore, the potential endemicity in DPRK and Malaysia is excluded from the estimation.

\section{Increasing trend in prevalence}

Compared to the estimation of 7 million population infected with clonorchiasis in 1990s [8], the number in 2004 had doubled. Drastic increase occurred in mainland of China, from 4.70 million to 12.49 million $[8,10,11]$. The prevalence in the Republic of Korea fluctuated, which declined from $4.6 \%$ in 1971 to $1.4 \%$ in 1997 and bounced 
to $2.4 \%$ in 2004 [17]. The pattern in Vietnam and other areas is unclear. In the endemic areas, on the one hand it is difficult for the elder preferring eating raw fish to modify diet habit, and on the other hand the younger gradually get accustomed to this habit. Furthermore, the growth of population and freshwater fish aquaculture are other important contributors. There was a growth of 102 million population in the three major endemic areas, namely China, the Republic of Korea and Vietnam from 1995 to 2004 [62]. Meanwhile, the production of freshwater fish has increased by $55 \%, 116 \%$ and $91 \%$ in the aforementioned countries [63].

\section{Variability among sexes and age}

The prevalence in the male is generally higher than that in the female. According to the special survey in 2004b in endemic areas of mainland of China, the prevalence was $2.94 \%$ in the male, while it was $1.84 \%$ in the female (Figure 2) $[10,11]$. The prevalence was $3.21 \%$ and $1.62 \%$ in the male and female respectively in the Republic of Korea's national survey in 2004 [17], and 13.60\% and $8.90 \%$ along 4 major rivers in 2006 [18]. Similarly, it was found that the prevalence in the male was 2-3 times or more than that in the female in local surveys in Vietnam [19]. Accordingly, among 15 million population infected, 9.6 million are male and 5.5 million are female (Table 1 ). The infection intensity is also higher in the male than that in the female. Taking the special survey in mainland of China in 2004b for example, those with moderate and heavy intensity (eggs per gram of feces $\geq 1000$ ) accounted for $28 \%$ in the male, while it was only $15 \%$ in the female $[10,11]$.

The prevalence increases with age and reaches the highest in the age group of 50-59 (Figure 3) $[10,11,17,18]$ or 40-49 (in local surveys in Vietnam) [19]. Similarly, the infection intensity also reaches the peak in the age group of $50-59$ [10,11].

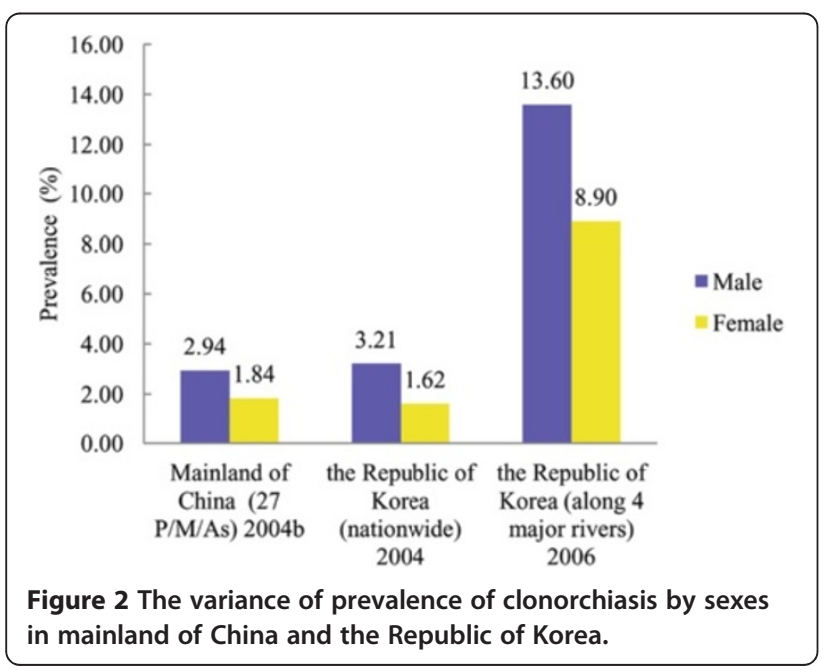

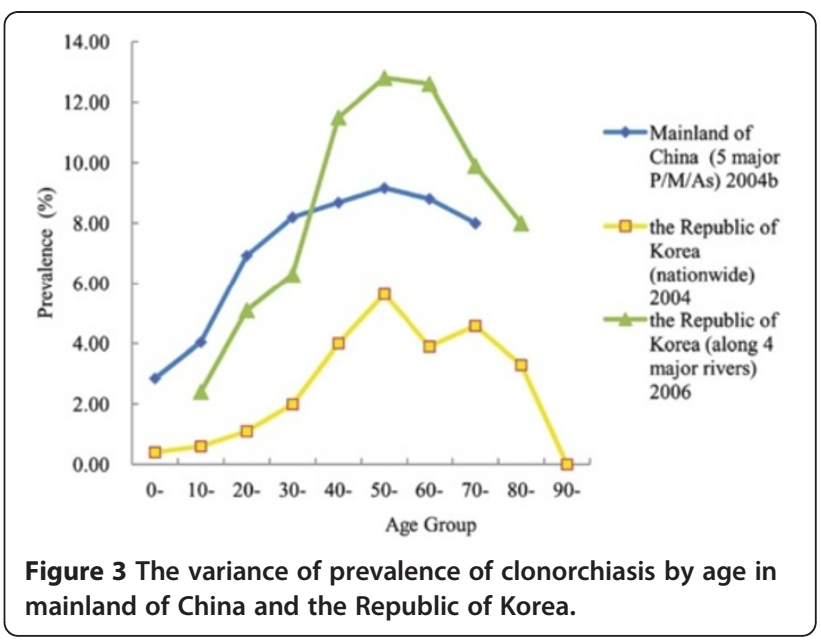

The distribution characteristics among sexes and age are mainly related to social customs, in other words, human raw-fish-eating behavior, and no yet evidence of concomitant immunity has been found to play important roles [64]. Raw fish is often consumed at restaurants or social parties, which the male have more chance to participate in $[11,23,64,65]$. Moreover, raw fish are often enjoyed over alcohol, which is more common among the male than the female and excludes children $[7,64]$. Furthermore, adult worms can survive in the body for decades $[52,64]$. Consequently, the exposure of the adult male is higher and so does the worm load, which leads to higher prevalence and infection intensity. However, in some local high endemic areas (prevalence over 60\%), there is no significant difference in prevalence by sexes $[66,67]$. The decline of prevalence in those older than 60 (50 in local surveys of Vietnam) is probably due to the early death caused by clonorchiasis-related complications [68]. We also argue that elderlies seek for medical services more frequently due to clonorchiasis-related complications or unrelated diseases, and then accept diagnosis and treatment. It's not surprising that the peak of $O$. viverrini infection also occurs in the age group of 50-59 in Thailand-the most endemic area of $O$. viverrini with an overall prevalence of $8.7 \%$ and over 6 million infected [22,69,70]. Although at low level, some children is also infected. In some areas of China, children like to ingest incompletely roasted small fish and get infected [10]. In the Republic of Korea, sometimes children are given raw fish by their mothers who think raw fish can make their children strong in traditional ideas $[64,71]$. However, in other areas, children are usually not allowed to eat raw fish [23].

\section{Endemicity}

Due to different distribution of intermediate host and food habit, the distribution of clonorchiasis also varies in different areas, measured by endemicity. In a global view, it mainly distributes in China, the Republic of Korea 
and Vietnam. However, the prevalence is various even in the same country. There are two major endemic regions in China, i.e. the southeast including Guangdong and Guangxi, and the northeast including Heilongjiang, Jilin and Liaoning, with the prevalence of $16.42 \%$, $9.76 \%, 4.73 \%, 2.90 \%$ and $0.80 \%$, respectively (Figure 4 ) $[10,11]$. The top four endemic areas in the Republic of Korea are Gyeongsangnam-do (11.3\%), Daejeon (6.9\%), Chungcheongnam-do (6.8\%) and Jeollanam-do (6.2\%), while there is no infection in Jeju-do (Figure 4) [17]. To current knowledge, clonorchiasis is endemic in 21 northern provinces of Vietnam (Figure 4) [20].

Thus, the distribution range of $C$. sinensis is mainly consisted of two epidemic zones. The first zone includes the southeast of China and the northern area of Vietnam, and the second one covers the northeast of China, the Republic of Korea, part of Russia and probably DPRK (Figure 4). The first zone neighbors to the endemic area of O. viverrini (mainly in Thailand, Laos, Cambodia and the southern part of Vietnam $[2,4,8,19,20,22,69,70])$, while the second one is adjacent to that of $O$. felineus (mainly in Russia [2,4,8,72]).

\section{Association of $C$. sinensis infection with CCA}

CCA, usually with poor prognosis, is a primary hepatic malignancy arising from bile duct epithelium and ranks the second most common primary hepatic malignancy [73-75]. The incidence of CCA varies greatly among different areas of the world and so does the constituent ratio of CCA in hepatic malignancy, which is related to the distribution of risk factors [76,77]. Liver fluke infection is just one important factor [74,76-78]. In 1994, $C$. sinensis and $O$. viverrini were classified as "probably carcinogenic to humans" (Group 2A) and "carcinogenic to humans" (Group 1) by IARC, respectively [79]. Based

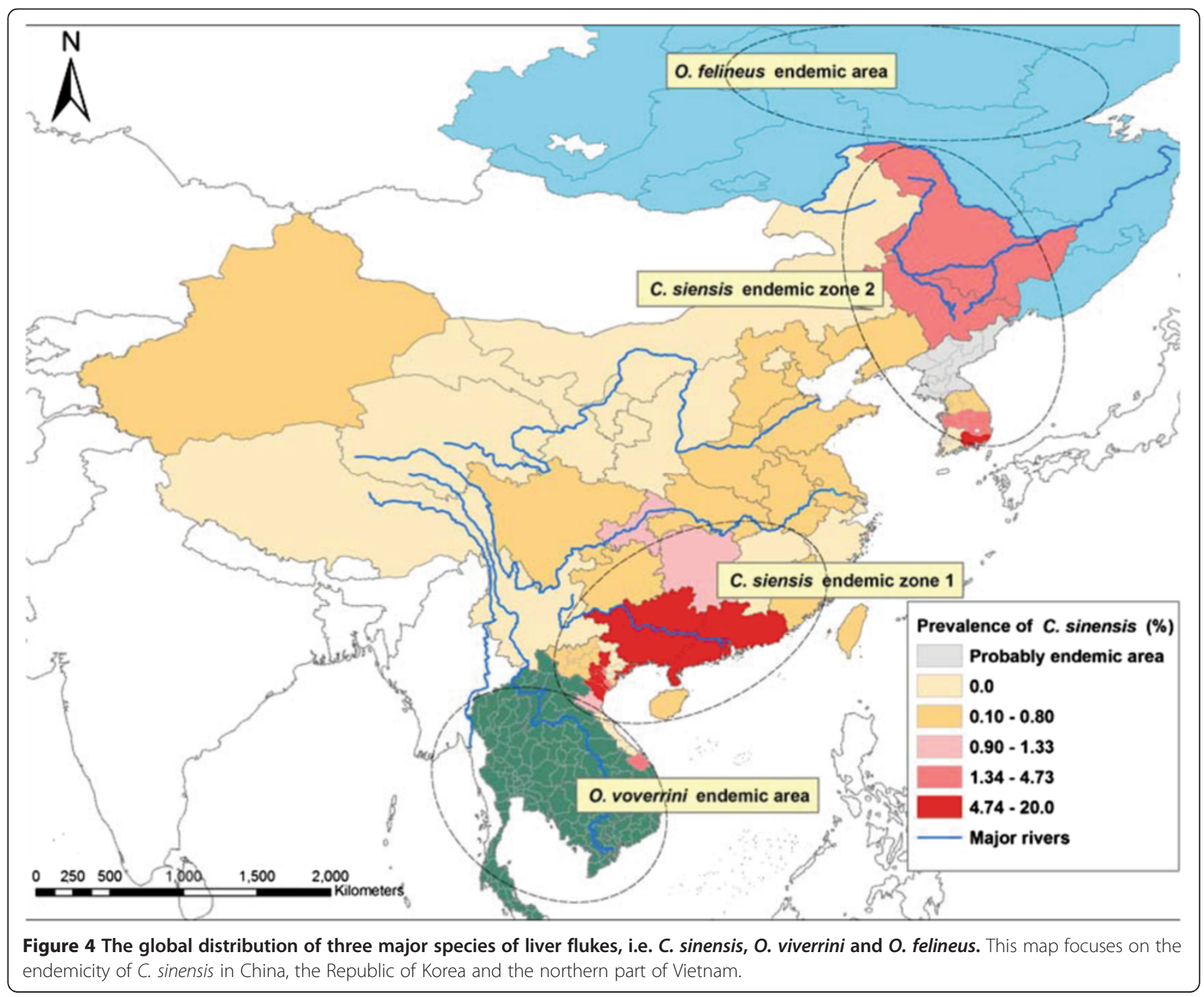


on more evidences, C. sinensis is reassessed as "carcinogenic to humans" (Group 1) in 2009 [5,6].

\section{The epidemiological studies}

Many reports on $C$. sinensis infection-related CCA have been documented. Cited here are 8 cross-sectional or case-control studies and relevant important information is extracted and listed in Additional file 2 [80-87].

During 1960s and 1970s, three cross-sectional studies were carried out in Hong Kong and the Republic of Korea, which preliminarily showed the probable carcinogenesis of $C$. sinensis infection to human (Group 2A) [80-82]. Three case-control studies in the Republic of Korea were then published between 1996 and 2008, which promoted the reassessment of it as "carcinogenic to humans" (Group 1) in 2009 [83-85]. Recently, another two case-control studies have also been reported in mainland of China, which further demonstrated the etiological relationship [86,87].

Some aspects deserve being emphasized. Firstly, ideally, the case and control represent the source population, otherwise there exists bias. C. sinensis infection mainly causes liver and biliary diseases, of which gallstone is very frequent $[88,89]$. Thus, the criteria for inclusion and exclusion of subjects are important. However, in one crosssectional study, the control consisted of those with liver disease, which biased to include those with $C$. sinensis infection [81]. In another case-control study, persons with stones in the bile ducts were excluded from the case, which biased to exclude those infected with $C$. sinensis [84]. Furthermore, in the same case-control study, many patients with alcohol induced pancreatitis were included as controls although they didn't have hepatobiliary diseases. However, it may also bias to include those with $C$. sinensis infection in the control. On the one hand, C. sinensis infection can induce pancreatitis [3,90-95]. On the other hand, raw-fish-eating habit is associated with alcohol drinking $[7,64]$. Therefore, the relationship intensity (odds ratio, OR) may be underestimated in above two studies. Secondly, the determination of exposure is another important problem, which may cause misclassification bias. When stool examination is adopted, the misclassification is prone to occur in the case, because bile obstruction usually occurs in CCA cases. For example, bile obstruction occurred in more than half of cases in one study, which led to contrary results when stool examination and pathological examination were adopted, respectively [84]. Additionally, the development of cancers is chronic with a long process and past exposure may also be risk factor. Therefore, serologic test and radiologic examination may be more sensitive, as past infection can also be detected [84]. It is regretting that no definite method for determining exposure was mentioned for the two studies in mainland of China $[86,87]$.
In addition to the studies listed in Additional file 2, one ecological study carried out in the Republic of Korea also showed the positive relationship [96]. The prevalence of clonorchiasis in Chuncheon, Chungju and Haman was $2.1 \%, 7.8 \%$ and $31.3 \%$, respectively, while the incidence of CCA was $0.3 / 100000,1.8 / 100000$ and 5.5/100 000, the proportion of CCA in liver cancer was $1.4 \%, 8.9 \%$ and $13.2 \%$, respectively. Furthermore, another case-control study was reported in mainland of China, but C. sinensis infection had only been tested in cases rather than controls [97].

\section{Estimation of CCA cases attributable to $C$. sinensis infection}

The estimation of CCA cases attributed to C. sinensis infection can be based on either formula below: $[98,99]$

$$
\begin{aligned}
& \text { CCAs attributed to C.sinensis } \\
& =\text { population infected } \\
& \times \text { CCA incidence of uninfected } \\
& \times(\text { odds ratio }-1) \\
& \text { CCAs attributed to } C \text {. sinensis } \\
& =\text { totalCCAs } \\
& \times\left\{\frac{\text { C.sinensis prevalence rate } *(\text { odds ratio }-1)}{[\text { C.sinensis prevalence rate } *(\text { odds ratio }-1)]+1} * 100 \%\right]
\end{aligned}
$$

Although different parameters are necessary in formula (1) and formula (2), the prevalence of $C$. sinensis and the population infected could be converted mutually. Obviously, no matter which formula is applied, the relationship intensity, namely OR, is of crucial importance.

Based on the studies shown in Additional file 2, the comprehensive OR can be deduced through meta-analysis. Original OR rather than adjusted one in each study is applied, because those studies had different objectives and designs and took into consideration of different aspects. The overall OR is 4.47 (95\% CI: 2.61-7.66) (RevMan software, http://ims.cochrane.org/revman) (Figure 5). Other researchers have done similar analysis. It was 4.65 (95\% CI: 2.21-9.79) through meta-analysis of the related studies in the Republic of Korea [99], while it was 4.84 (95\% CI: 2.79-8.41) after including those studies pertaining to O. viverrini infection and CCA [77,100-103].

Shin et al. have managed to estimate clonorchiasisinduced CCA in the Republic of Korea [99]. Due to lack of CCA data in other $C$. sinensis endemic areas, that in the Republic of Korea will be extrapolated (Table 2). Firstly, based on formula (2), the number of CCA cases in the Republic of Korea (2 166 male and 1440 female in 2005 [99]), C. sinensis prevalence (3.7\% in the male and $1.6 \%$ in the female in 1981 [17]) and the overall OR (4.47), 


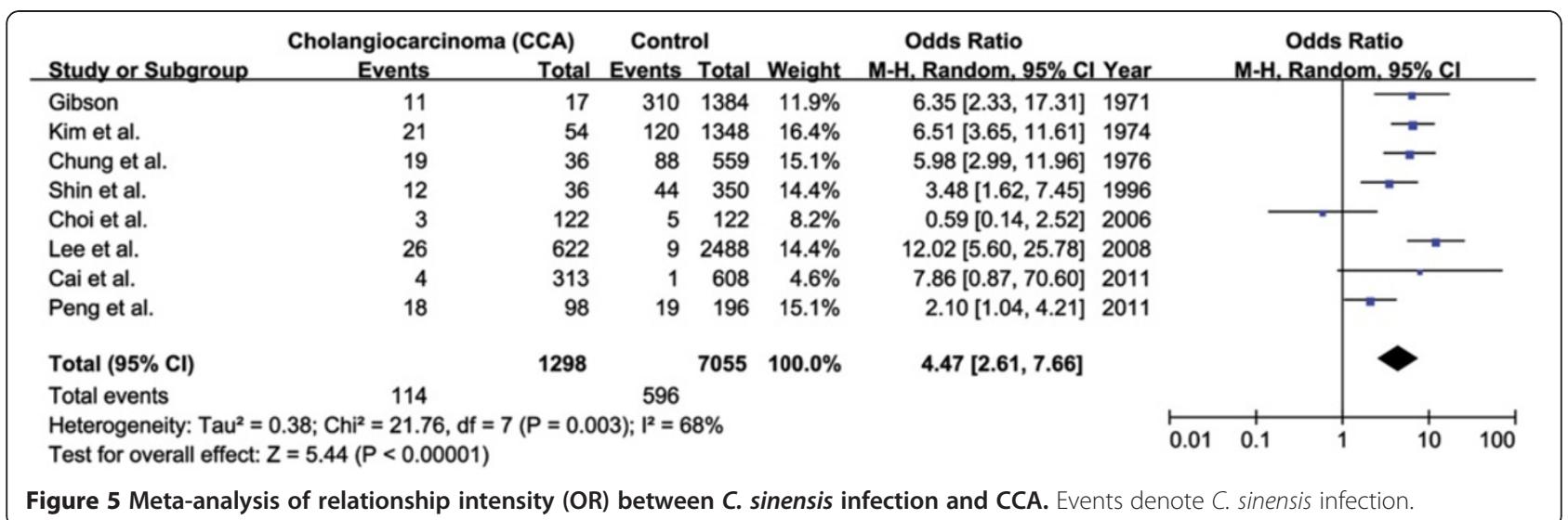

it is estimated that 246 male and 76 female CCA cases attributed to $C$. sinensis infection occurred in the Republic of Korea in 2005. Secondly, according to the clonorchiasis-related CCA cases occurring in the Republic of Korea in 2005 and the population infected with $C$. sinensis in 1981, the incidence of CCA among C. sinensis infected population is deduced, namely 35/100 000 and $25 / 100000$ in the male and female, respectively. Thirdly, after multiplying the global population infected, the global CCA cases attributed to C. sinensis infection are captured, namely 4 726, of which 3345 are male and 1381 are female (Table 2). It must be cautious that the morbidity of cancer is a chronic progress spanning several decades. Thus, the prevalence of C. sinensis in 1981 was adopted, while CCA cases in 2005 were applied [99]. Likewise, the deduced global clonorchiasis-related CCA cases may occur several decades later theoretically.

One obvious limitation is that no individual OR has been available for the male and female, respectively. In the study focusing on the relationship between $O$. viverrini infection and CCA, it was found the higher the infection intensity, the higher the OR [102]. Furthermore, compared to the female, the male infected have higher infection intensity as was depicted above $[10,11]$. Thus, it is reasonable to assume different ORs should be offered for different sexes. However, due to lack of such data, only the same OR is adopted here.

\section{Conclusion}

A conservative estimation was made that 15 million people were infected with $C$. sinensis in 2004 in east Asia, especially in China, the Republic of Korea and Vietnam, which may cause nearly 5000 CCA cases annually in the future. Although the population infected is relatively smaller compared to schistosomiasis and soil-transmitted helminthiases, the distribution is highly concentrated in several Asian countries, where the public health is being threatened severely. Furthermore, the impact is increasing and expanding to non-endemic areas due to the growth and movement of population and the rapid development of aquaculture. Thus, it is listed among the most neglected tropical diseases $[7,104]$. Fortunately, the evaluation on the burden of food-borne diseases was launched by WHO in 2006 and clonorchiasis and other liver fluke diseases were included [105]. The assessment of disease burden promotes the awareness of harm, adoption of intervention and evaluation of cost-effectiveness. Epidemiological data are the basis of assessment of disease burden. Only when the data are available, can disease burden be calculated objectively. CCA is the most severe and fatal outcome caused by $C$. sinensis infection, which predominantly constitutes the mortality lost of disease burden in term of disability-adjusted life years [106]. Therefore, the epidemiological data on CCA is also crucial. It is expected the deduced data on population infected and CCA cases here will benefit the evaluation of disease burden of clonorchiasis, which will promote the control and prevention ultimately.

However, further researches on epidemiology of clonorchiasis and CCA should be carried out. Although nation-wide surveys have been carried out in China and the Republic of Korea, the epidemiological status in Vietnam is not yet clear and thus nationally sampling survey would be expected. Whether there exist local transmission and even epidemicity in DPRK and Malaysia also needs to be solved. Another important issue is the species discrimination, which may turn to the molecular biology techniques. Now that Kato-Katz technique is still the major diagnosis method as it is pathogen-oriented, convenient and at low cost, how to reduce the underestimation especially in low infection level is important. The accurate evaluation of prevalence will promote the adoption of suitable intervention and objective evaluation of disease burden. New techniques such as model simulation may deserve being introduced. Further studies on the relationship between $C$. sinensis infection and CCA are also expected, especially the separate OR for different sexes. The determination of exposure should also be further 
Table 2 The estimated incidence of CCA among population infected with C. sinensis and CCA cases attributable to C. sinensis infection globally

Sex

Total CCA cases
in the Republic

C. sinensis

prevalence in

OR $(95 \% \mathrm{Cl})$

the Republic

of Korea in

\section{CCA cases}

attributable to

Population in

Population infected

C. sinensis infection

Korea in $1981^{\star}$

Korea in 1981

CCA incidence
in infected

in infected

Global population

in the Republic of

$(95 \% \mathrm{Cl})$

infected in 2004

Korea $(95 \% \mathrm{Cl})$

$35(17-61)$

$3.70 \%$

4.47 (2.61-7.66)

246 (122-428)

19041203

$4.47(2.61-7.66)$

76 (36-139)

19013400

704525
304214

$25(12-46)$

9563589

5546755

\section{CCA cases}

attributable to

C. sinensis infection

Globally $(95 \% \mathrm{Cl})$

Total

${ }^{\#}$ Reference [99]; ${ }^{*}$ Reference [17]; ${ }^{\star}$ Reference [62]. 
approached. The progress of CCA is chronic and complicated in which various factors are involved. Consequently, the public health impact of clonorchiasis is remarkably indicated by the above mentioned result that the deduced CCA cases are significantly attributed to $C$. sinensis infection with an overall OR of 4.47, although the result here may not be highly accurate. As it should be, new methods are expected to be applied and more accurate data to be captured.

\section{Additional file}

\section{Additional file 1: Multilingual abstracts in the six official working languages of the United Nations. \\ Additional file 2: Epidemiological studies on the relationship between $C$. sinensis infection and CCA.}

\section{Competing interests}

The authors declare that they have no competing interests.

\section{Authors' contributions}

$\mathrm{M}-\mathrm{BQ}$ and $\mathrm{X}-\mathrm{NZ}$ designed the study. $\mathrm{M}-\mathrm{BQ}$ and $\mathrm{Y}-\mathrm{DC}$ collected the data $\mathrm{M}-\mathrm{BQ}, \mathrm{SL}$ and $\mathrm{G}-J Y$ analyzed the data. M-BQ and $\mathrm{X}-\mathrm{NZ}$ wrote the paper. All authors read and approved the manuscript.

\section{Acknowledgments}

We are grateful to Carlos A.M. Lima dos Santos in Brazil for his kindly presentation of some papers on the epidemiology of Clonorchis sinensis in Malaysia. This project is funded through a capacity building initiative for Ecohealth Research on Emerging Infectious Disease in Southeast Asia supported by the International Development Research Centre (IDRC), the Canadian International Development Agency (CIDA), and the Australian Agency for International Development (AusAID) in partnership with the Global Health Research Initiative (grant No. 105509-00001002-023), as well as supported by the National S \& T Major Program (grant No. 2008ZX10004011), and by the National S \& T Supporting Project (grant No. 2007BAC03A02). Zhou XN was supported by Shanghai S\&T Committee (grant No. 11XD1405400).

\section{Author details}

${ }^{1}$ National Institute of Parasitic Diseases, Chinese Center for Disease Control and Prevention; WHO Collaborative Center for Malaria, Schistosomiasis and Filariasis; Key Laboratory of Parasite and Vector Biology, Ministry of Health, Shanghai, People's Republic of China. ${ }^{2}$ Department of Environmental and Global Health, College of Public Health and Health Professions, and Emerging Pathogens Institute, University of Florida, Gainesville, USA. ${ }^{3}$ Jiangsu Institute of Parasitic Diseases, Wuxi, People's Republic of China. ${ }^{4}$ School of Public Health, Chinese University of Hong Kong, Hong Kong, People's Republic of China.

Received: 23 August 2012 Accepted: 24 September 2012 Published: 25 October 2012

\section{References}

1. Lun ZR, Gasser RB, Lai DH, Li AX, Zhu XQ, Yu XB, Fang YY: Clonorchiasis: a key foodborne zoonosis in China. Lancet Infect Dis 2005, 5:31-41.

2. Keiser J, Utzinger J: Emerging foodborne trematodiasis. Emerg Infect Dis 2005, 11:1507-1514.

3. Keiser J, Utzinger J: Food-borne trematodiases. Clin Microbiol Rev 2009, 22:466-483

4. Sripa B, Kaewkes S, Intapan PM, Maleewong W, Brindley PJ: Food-borne trematodiases in Southeast Asia: epidemiology, pathology, clinical manifestation and control. Adv Parasitol 2010, 72:305-350.

5. Bouvard V, Baan R, Straif K, Grosse Y, Secretan B, El Ghissassi F, Benbrahim-Tallaa L, Guha N, Freeman C, Galichet L, Cogliano V, WHO
International Agency for Research on Cancer Monograph Working Group: A review of human carcinogens--Part B: biological agents. Lancet Oncol 2009, 10:321-322.

6. International Agency for Research on Cancer: A Review of Human Carcinogens Part B: Biological Agents. IARC monographs on the evaluation of carcinogenic risks to humans. Lyon: IARC; 2011.

7. First WHO report on neglected tropical diseases 2010: working to overcome the global impact of neglected tropical diseases.; [http://www.who.int/ neglected_diseases/2010report/en/]

8. WHO: Control of Foodborne Trematode Infections, WHO Technical Report Series, Volume 849. Geneva; World Health Organization; 1995.

9. Yu SH, Xu LQ, Jiang ZX, Xu SH, Han JJ, Zhu YG, Chang J, Lin JX, Xu FN: Nationwide survey of human parasite in China. Southeast Asian J Trop Med Public Health 1994, 25:4-10.

10. Technical Steering Panel for National Survey of Current Status of Major Human Parasitic Diseases: Report on the National Survey of Current Status of Major Human Parasitic Diseases in China. Beijing: People's Medical Publishing House; 2008.

11. Fang YY, Chen YD, Li XM, Wu J, Zhang QM, Ruan CW: Current prevalence of Clonorchis sinensis infection in endemic areas of China. Chin J Parasitol Parasit Dis 2008, 26:99-103. in Chinese.

12. Chen ER: Clonorchiasis in Taiwan. Southeast Asian J Trop Med Public Health 1991, 22(Suppl):184-185.

13. Fan PC: Regional distribution of human parasitic infection in Taiwan province. In Distribution and pathogenic impact of human parasites in China. 1 st edition. Edited by Xu LQ, Yu SH, Xu SH. Beijing: People's Medical Publishing House; 2000:262-279. in Chinese.

14. National Bureau of Statistics of the People's Republic of China, Communiqué on Major Figures of the Population Census. [http://www.stats.gov.cn/tigb/ $\mathrm{rkpcgb/]}$

15. Zheng $X B$, Ling ML: Status of intestinal parasitic infections in Hong Kong In Distribution and pathogenic impact of human parasites in China. 1st edition. Edited by Xu LQ, Yu SH, Xu SH. Beijing: People's Medical Publishing House; 2000:279-282. in Chinese.

16. Qu GY: Status of human parasitic infections in Macao. In Distribution and pathogenic impact of human parasites in China. 1st edition. Edited by Xu LQ Yu SH, Xu SH. Beijing: People's Medical Publishing House; 2000:282-286. in Chinese.

17. Kim TS, Cho SH, Huh S, Kong Y, Sohn WM, Hwang SS, Chai JY, Lee SH, Park YK, Oh DK, Lee JK, Working Groups in National Institute of Health; Korea Association of Health Promotion: A nationwide survey on the prevalence of intestinal parasitic infections in the Republic of Korea, 2004. Korean J Parasitol 2009, 47:37-47.

18. Cho SH, Lee KY, Lee BC, Cho PY, Cheun HI, Hong ST, Sohn WM, Kim TS: Prevalence of clonorchiasis in southern endemic areas of Korea in 2006. Korean J Parasitol 2008, 46:133-137.

19. De NV, Murrell KD, le Cong D, Cam PD, le Chau V, Toan ND, Dalsgaard A: The food-borne trematode zoonoses of Vietnam. Southeast Asian J Trop Med Public Health 2003, 34(Suppl 1):12-34.

20. De NV, Le TH: Current status of opisthorchiasis in Vietnam. In Proceedings \& Abstracts: 96 Years of Opisthorchiasis, International Congress of Liver Flukes: 7-8, March 2011. Thailand: Khon Kaen; 2011:49-51.

21. Trung Dung D, Van De N, Waikagul J, Dalsgaard A, Chai JY, Sohn WM, Murrell KD: Fishborne zoonotic intestinal trematodes, Vietnam. Emerg Infect Dis 2007, 13:1828-1833.

22. WHO: Report of the WHO Expert Consultation on Foodborne Trematode Infections and Taeniasis/Cysticercosis. Vientiane: World Health Organization; 2009.

23. Phan VT, Ersbøll AK, Do DT, Dalsgaard A: Raw-fish-eating behavior and fishborne zoonotic trematode infection in people of northern Vietnam. Foodborne Pathog Dis 2011, 8:255-260.

24. Traub RJ, Macaranas J, Mungthin M, Leelayoova S, Cribb T, Murrell KD, Thompson RC: A new PCR-based approach indicates the range of Clonorchis sinensis now extends to Central Thailand. PLoS Negl Trop Dis 2009, 3:e367.

25. Shen C, Li S, Zheng S, Choi MH, Bae YM, Hong ST: Tissue parasitic helminthiases are prevalent at Cheongjin, North Korea. Korean J Parasitol 2007, 45:139-144.

26. Shekhar KC, Nazarina AR, Lee SH, Pathmanathan R: Clonorchiasis/ opisthorchiasis in Malaysians case reports and review. Med J Malaysia 1995, 50:182-186. 
27. Jamaiah I, Rohela M: Prevalence of intestinal parasites among members of the public in Kuala Lumpur, Malaysia. Southeast Asian J Trop Med Public Health 2005, 36:68-71.

28. Rohela M, Johari S, Jamaiah I, Init I, Lee SH: Acute cholecystitis caused by Clonorchis sinensis. Southeast Asian J Trop Med Public Health 2006 37:648-651.

29. Bisseru B: Clonorchis sinensis in West Malaysia. Trop Geogr Med 1970, 22:352-356.

30. Shekhar KC: Epidemiological aspects of aquaculture in relation to fish borne trematodiasis in Malaysia. Southeast Asian J Trop Med Public Health 1997, 28(Suppl 1):54-57.

31. Carlos AM, Lima dos Santos, Howgate P: Fishborne zoonotic parasites and aquaculture: a review. Aquaculture 2011, 318:253-261.

32. Nakamura-Uchiyama F, Hiromatsu K, Ishiwata K, Sakamoto Y, Nawa Y: The current status of parasitic diseases in Japan. Intern Med 2003, 42:222-236.

33. Onodera S, Saito K, Saito T, Togashi H, Kawata S, Ukai K, Shinzawa H: Clonorchiasis complicated with duodenal papillary cancer in a visitor from China. Nippon Shokakibyo Gakkai Zasshi 2007, 104:213-218. in Japanese.

34. Mirdha BR, Gulati S, Sarkar T, Samantray JC: Acute clonorchiasis in a child. Indian J Gastroenterol 1998, 17:155.

35. Tan WB, Shelat VG, Diddapur RK: Oriental liver fluke infestation presenting more than 50 years after immigration. Ann Acad Med Singapore 2009, 38:735-736.

36. Kuzmicki R, Dzieciolowski Z, Borowska-Kuzmicka J: A case of Clonorchis sinensis infection. Pol Tyg Lek (Wars) 1959, 14:819-821 (in Polish).

37. Kuźmicki R, Gajda E, Switalska-Kowalewska E: 2 cases of Clonorchis sinensis infection with associated infestation with other parasites. Wiad Lek 1966 19:325-328 (in Polish)

38. Ziegler K, Osten M, Lafrenz M, Möller FW: Human infestation with liver flukes. Z Gesamte Inn Med 1975, 30:344-346 (in German)

39. Hartley JP, Douglas AP: A case of clonorchiasis in England. Br Med J 1975, 3:575

40. Holler A, Blanchon P, Lapierre J, Holler C: Letter: Distomatosis with Clonorchis sinensis diagnosed by hepatic puncture biopsy. Nouv Presse Med 1976, 5:39 (in French).

41. Taat CW: Acute cholecystitis and clonorchis sinensis infection. Ned Tijdschr Geneeskd 1981, 125:2008-2012 (in Dutch).

42. Wahlgren $M$, Wihlborg B, Liljeqvist L: Clonorchiasis-an unusual cause of cholangitis. Lakartidningen 1983, 80:153-154 (in Swedish).

43. Dennis MJ, Dennison AR, Morris DL: Parasitic causes of obstructive jaundice. Ann Trop Med Parasitol 1989, 83:159-161.

44. Poinsignon Y, Mounier N, Fritsch S, Sarfati C, Farge-Bancel D: Cholangitis due to Clonorchis sinensis detected in Escherichia coli septic shock. Med Trop (Mars) 1996, 56:203 (in French).

45. Stunell H, Buckley O, Geoghegan T, Torreggiani WC: Recurrent pyogenic cholangitis due to chronic infestation with Clonorchis sinensis (2006: 8b). Eur Radiol 2006, 16:2612-2614.

46. Ciprandi G, Cavallucci E, Cuccurullo F, Di Gioacchino M: Helminthic infection as a factor in new-onset coffee allergy in a father and daughter. J Allergy Clin Immunol 2008, 121:773-774.

47. Dixon BR, Flohr RB: Fish- and shellfish-borne trematode infections in Canada. Southeast Asian J Trop Med Public Health 1997, 28(Suppl 1):58-64.

48. Fried B, Abruzzi A: Food-borne trematode infections of humans in the United States of America. Parasitol Res 2010, 106:1263-1280.

49. Calero C: Clonorchiasis in Chinese residents of Panama. J Parasitol 1967, 53:1150.

50. Oostburg BF, Smith SJ: Clonorchiasis in Surinam. Trop Geogr Med 1981, 33:287-289.

51. Gómez N, Urrea I, Astudillio R: Primary epidermoid carcinoma of the gallbladder. Acta Gastroenterol Latinoam 1990, 20:169-173.

52. Attwood HD, Chou ST: The longevity of Clonorchis sinensis. Pathology 1978, 10:153-156.

53. Morsy AT, Al-Mathal EM: Clonorchis sinensis a new report in Egyptian employees returning back from Saudi Arabia. J Egypt Soc Parasitol 2011 41:221-225

54. Kaewkes S: Taxonomy and biology of liver flukes. Acta Trop 2003 88:177-186.

55. Johansen MV, Sithithaworn P, Bergquist R, Utzinger J: Towards improved diagnosis of zoonotic trematode infections in Southeast Asia. Adv Parasitol 2010, 73:171-195.
56. Sithithaworn P, Tesana S, Pipitgool V, Kaewkes S, Pairojkul C, Sripa B, Paupairoj A, Thaiklar K: Relationship between faecal egg count and worm burden of Opisthorchis viverrini in human autopsy cases. Parasitology 1991, 102(Pt 2):277-281.

57. Utzinger J, Rinaldi L, Lohourignon LK, Rohner F, Zimmermann MB, Tschannen AB, N'goran EK, Cringoli G: FLOTAC: a new sensitive technique for the diagnosis of hookworm infections in humans. Trans $R$ Soc Trop Med Hyg 2008, 102:84-90.

58. Lin DD, Liu JX, Liu YM, Hu F, Zhang YY, Xu JM, Li JY, Ji MJ, Bergquist R, Wu $\mathrm{GL}$, Wu HW: Routine Kato-Katz technique underestimates the prevalence of Schistosoma japonicum: a case study in an endemic area of the People's Republic of China. Parasitol Int 2008, 57:281-286.

59. Knopp S, Rinaldi L, Khamis IS, Stothard JR, Rollinson D, Maurelli MP, Steinmann $P$, Marti $H$, Cringoli $G$, Utzinger J: A single FLOTAC is more sensitive than triplicate Kato-Katz for the diagnosis of low-intensity soil-transmitted helminth infections. Trans R Soc Trop Med Hyg 2009, 103:347-354

60. Knopp S, Glinz D, Rinaldi L, Mohammed KA, N'Goran EK, Stothard JR, Mart $H$, Cringoli G, Rollinson D, Utzinger J: FLOTAC: a promising technique for detecting helminth eggs in human faeces. Trans $R$ Soc Trop Med Hyg 2009, 103:1190-1194.

61. Glinz D, Silué KD, Knopp S, Lohourignon LK, Yao KP, Steinmann P Rinaldi L, Cringoli G, N'Goran EK, Utzinger J: Comparing diagnostic accuracy of Kato-Katz, Koga agar plate, ether-concentration, and FLOTAC for Schistosoma mansoni and soil-transmitted helminths. PLoS Negl Trop Dis 2010, 4:e754

62. United Nations, Population Division, Department of Economic and Social Affairs, World Population Prospects: The 2010 Revision [http://esa.un.org/ unpd/wpp/Excel-Data/population.htm]

63. Food and Agriculture Organization of the United Nations, Fisheries and Aquaculture Department: Fishery Statistical Collections: Consumption of Fish and Fishery Products [http://www.fao.org/fishery/statistics/globalconsumption/en]

64. Chen MG, Lu Y, Hua XJ, Mott KE: Progress in assessment of morbidity due to clonorchis sinensis infection: a review of recent literature. Trop Dis Bull 1994, 91:R7-R65.

65. Nontasut P, Thong TV, Waikagul J, Anantaphruti MT, Fungladda W, Imamee N, De NV: Social and behavioral factors associated with Clonorchis infection in one commune located in the Red River Delta of Vietnam. Southeast Asian J Trop Med Public Health 2003, 34:269-273.

66. Duan JH, Tang XY, Wang QZ, Tang Y, Zhang ZS, Li ZX, Liu AH, Wu YJ, Chen WH, Huang QR: Epidemiological Survey on Clonorchiasis sinensis in an Endemic Area of South Hunan Province. Chin J Parasitol Parasit Dis 2009 27:467-471 (in Chinese)

67. Disease Control Bureau of Ministry of Health of the People's Republic of China and Chinese Center for Disease Control and Prevention: Assessing report of the comprehensive demonstrating zones for controlling and treating of parasitic diseases between 2006 and 2009. Beijing; People's Medical Publishing House; 2010.

68. Choi Bl, Han JK, Hong ST, Lee KH: Clonorchiasis and cholangiocarcinoma: etiologic relationship and imaging diagnosis. Clin Microbiol Rev 2004, 17:540-552

69. Wattanayingcharoenchai S: National survey of Opisthorchis viverrini in Thailand: current situation and control. In Proceedings \& Abstracts: 96 Years of Opisthorchiasis, International Congress of Liver Flukes: 7-8, March 2011. Thailand: Khon Kaen; 2011:35

70. Sithithaworn $\mathrm{P}$, Andrews $\mathrm{RH}$, Van De N, Wongsaroj $T$, Sinuon $M$, Odermatt P, Nawa Y, Liang S, Brindley PJ, Sripa B: The current status of opisthorchiasis and clonorchiasis in the Mekong Basin. Parasitol Int 2012, 61(1):10-16

71. Choi DW: Clonorchis sinensis: life cycle, intermediate hosts, transmission to man and geographical distribution in Korea. Arzneimittelforschung 1984, 34(9B):1145-1151.

72. Mordvinov VA, Yurlova NI, Ogorodova LM, Katokhin AV: Opisthorchis felineus and Metorchis bilis are the main agents of liver fluke infection of humans in Russia. Parasitol Int 2012, 61(1):25-31.

73. Blechacz BR, Gores GJ: Cholangiocarcinoma. Clin Liver Dis 2008, 12:131-150. ix.

74. Khan SA, Toledano MB, Taylor-Robinson SD: Epidemiology, risk factors, and pathogenesis of cholangiocarcinoma. HPB (Oxford) 2008, 10:77-82.

75. Mosconi S, Beretta GD, Labianca R, Zampino MG, Gatta G, Heinemann V: Cholangiocarcinoma. Crit Rev Oncol Hematol 2009, 69:259-270. 
76. Shaib Y, El-Serag HB: The epidemiology of cholangiocarcinoma. Semin Liver Dis 2004, 24:115-125.

77. Shin HR, Oh JK, Masuyer E, Curado MP, Bouvard V, Fang YY, Wiangnon S, Sripa B, Hong ST: Epidemiology of cholangiocarcinoma: an update focusing on risk factors. Cancer Sci 2010, 101:579-585.

78. Sripa B, Kaewkes S, Sithithaworn P, Mairiang E, Laha T, Smout M, Pairojkul C, Bhudhisawasdi V, Tesana S, Thinkamrop B, Bethony JM, Loukas A, Brindley PJ: Liver fluke induces cholangiocarcinoma. PLoS Med 2007, 4:e201.

79. International Agency for Research on Cancer: Schistosomes, liver flukes and Helicobacter pylori. IARC monographs on the evaluation of carcinogenic risks to humans. Lyon; IARC; 1994.

80. Gibson JB: Parasites, Liver Disease and Liver Cancer. Lyon: IARC; 1971.

81. Kim YI, Yang DH, Chang KR: Relationship between Clonorchis sinensis infestation and cholangiocarcinoma of the liver in Korea. Seoul J Med 1974, 15:247-253 (in Korean).

82. Chung CS, Lee SK: An epidemiological study of primary liver carcinomas in Busan area with special reference to clonorchis. Korean J Pathol 1976, 10:33-46 (in Korean).

83. Shin HR, Lee CU, Park HJ, Seol SY, Chung JM, Choi HC, Ahn YO, Shigemastu T: Hepatitis B and C virus, Clonorchis sinensis for the risk of liver cancer: a case-control study in Pusan, Korea. Int J Epidemiol 1996, 25:933-940.

84. Choi D, Lim JH, Lee KT, Lee JK, Choi SH, Heo JS, Jang KT, Lee NY, Kim S, Hong ST: Cholangiocarcinoma and Clonorchis sinensis infection: a case-control study in Korea. J Hepatol 2006, 44:1066-1073.

85. Lee TY, Lee SS, Jung SW, Jeon SH, Yun SC, Oh HC, Kwon S, Lee SK, Seo DW, Kim MH, Suh DJ: Hepatitis B virus infection and intrahepatic cholangiocarcinoma in Korea: a case-control study. Am J Gastroenterol 2008, 103:1716-1720.

86. Cai WK, Sima H, Chen BD, Yang GS: Risk factors for hilar cholangiocarcinoma: A case-control study in China. World I Gastroenterol 2011, 17:249-253

87. Peng NF, Li LQ, Qin $X$, Guo Y, Peng T, Xiao KY, Chen XG, Yang YF, Su ZX, Chen B, Su M, Qi LN: Evaluation of risk factors and clinicopathologic features for intrahepatic cholangiocarcinoma in Southern China: a possible role of hepatitis B virus. Ann Surg Oncol 2011, 18:1258-1266.

88. Rim HJ: Clonorchiasis: an update. J Helminthol 2005, 79:269-281.

89. Choi D, Lim JH, Lee KT, Lee JK, Choi SH, Heo JS, Choi DW, Jang KT, Lee NY, Kim S, Hong ST: Gallstones and Clonorchis sinensis infection: a hospitalbased case-control study in Korea. J Gastroenterol Hepatol 2008, 23(8 Pt 2):e399-e404.

90. McFadzean AJ, Yeung RT: Acute pancreatitis due to Clonorchis sinensis. Trans R Soc Trop Med Hyg 1966, 60:466-470.

91. Choi TK, Wong J: Severe acute pancreatitis caused by parasites in the common bile duct. J Trop Med Hyg 1984, 87:211-214.

92. Balthazar EJ, Lamb T: CT of Clonorchis Sinensis pancreatitis. Int J Pancreatol 1993, 14:189-194.

93. Kim YH: Pancreatitis in association with Clonorchis sinensis infestation: CT evaluation. AJR Am J Roentgenol 1999, 172:1293-1296.

94. Yang LC, Huang BY, Xue GF, Li XL, Mo DL: Relationship between infection of Clonorchis sinensis and hepatobiliary and pancreatic diseases. Chin J Hepatobiliary Surg 2004, 10:165-166 (in Chinese).

95. Huang H, Jia LP, Xie CS, Gu YP, Wang HX: Analysis on etiology of acute pancreatitis in Nanhai region of Guangdong province. Chin J Integr Trad West Med Dig 2005, 13:43-44 (in Chinese)

96. Lim MK, Ju YH, Franceschi S, Oh JK, Kong HJ, Hwang SS, Park SK, Cho SI, Sohn WM, Kim DI, Yoo KY, Hong ST, Shin HR: Clonorchis sinensis infection and increasing risk of cholangiocarcinoma in the Republic of Korea. Am J Trop Med Hyg 2006, 75:93-96.

97. Zhou YM, Yin ZF, Yang JM, Li B, Shao WY, Xu F, Wang YL, Li DQ: Risk factors for intrahepatic cholangiocarcinoma: a case-control study in China. World I Gastroenterol 2008, 14:632-635.

98. Parkin DM: The global health burden of infection-associated cancers in the year 2002. Int I Cancer 2006, 118:3030-3044

99. Shin HR, Oh JK, Lim MK, Shin A, Kong HJ, Jung KW, Won YJ, Park S, Park SJ, Hong ST: Descriptive epidemiology of cholangiocarcinoma and clonorchiasis in Korea. J Korean Med Sci 2010, 25:1011-1016.

100. Kurathong S, Lerdverasirikul P, Wongpaitoon V, Pramoolsinsap C, Kanjanapitak A, Varavithya W, Phuapradit P, Bunyaratvej S, Upatham ES,
Brockelman WY: Opisthorchis viverrini infection and cholangiocarcinoma. A prospective, case-controlled study. Gastroenterology 1985, 89:151-156.

101. Parkin DM, Srivatanakul P, Khlat M, Chenvidhya D, Chotiwan P, Insiripong S, L'Abbé KA, Wild CP: Liver cancer in Thailand. I. A case-control study of cholangiocarcinoma. Int J Cancer 1991, 8:323-328.

102. Haswell-Elkins MR, Mairiang E, Mairiang P, Chaiyakum J, Chamadol N, Loapaiboon V, Sithithaworn P, Elkins DB: Cross-sectional study of Opisthorchis viverrini infection and cholangiocarcinoma in communities within a high-risk area in northeast Thailand. Int J Cancer 1994, 59:505-509.

103. Honjo S, Srivatanakul P, Sriplung H, Kikukawa H, Hanai S, Uchida K, Todoroki T, Jedpiyawongse A, Kittiwatanachot P, Sripa B, Deerasamee S, Miwa M: Genetic and environmental determinants of risk for cholangiocarcinoma via Opisthorchis viverrini in a densely infested area in Nakhon Phanom, northeast Thailand. Int I Cancer 2005, 117:854-860.

104. Sripa B: Concerted action is needed to tackle liver fluke infections in Asia. PLoS Negl Trop Dis 2008, 2:e232.

105. WHO Initiative to estimate the Global Burden of Foodborne Diseases [http:// www.who.int/foodsafety/foodborne_disease/ferg/en/index.html]

106. Qian MB, Chen YD, Fang YY, Xu LQ, Zhu TJ, Tan T, Zhou CH, Wang GF, Jia TW, Yang GJ, Zhou XN: Disability Weight of Clonorchis sinensis Infection: Captured from Community Study and Model Simulation. PLoS Negl Trop Dis 2011, 5:e1377.

doi:10.1186/2049-9957-1-4

Cite this article as: Qian et al:: The global epidemiology of clonorchiasis and its relation with cholangiocarcinoma. Infectious Diseases of Poverty $20121: 4$

\section{Submit your next manuscript to BioMed Central and take full advantage of:}

- Convenient online submission

- Thorough peer review

- No space constraints or color figure charges

- Immediate publication on acceptance

- Inclusion in PubMed, CAS, Scopus and Google Scholar

- Research which is freely available for redistribution 